Erratum

\title{
Erratum: Primary Biliary Cirrhosis and Primary Sclerosing Cholangitis: a Review Featuring a Women's Health Perspective
}

\author{
The JCTH staff
}

\begin{abstract}
The authors have notified us of an error in the order of authorship. The correct order of authorship should be: Renée M. Marchioni Beery, Faripour Forouhar and Haleh Vaziri.

(C) 2015 The Second Affiliated Hospital of Chongqing Medical University. Published by XIA \& HE Publishing Ltd. All rights reserved.
\end{abstract}

DOI: $10.14218 / \mathrm{JCTH} .2015 .00101$ 